\title{
An in vitro study of the effect of blood and saliva contamination on the bond strength of self-etch and total- etch adhesive systems to dentine
}

\author{
Hussa ALHussain ${ }^{1}$, Kaltham ALUmairi ${ }^{1}$, Maha ALZahrani ${ }^{1}$, Tagreed bin Salman ${ }^{1}$ and Shibu Mathew ${ }^{2}$ \\ ${ }^{1}$ Dental Intern, Riyadh colleges of Dentistry and Pharmacy, Saudi Arabia \\ ${ }^{2} \mathrm{MDS}$, Assistant Professor Endodontic division, Riyadh colleges of Dentistry and Pharmacy, Saudi Arabia
}

\begin{abstract}
Objectives: Evaluate and compare the effect of saliva and blood contamination on dentine during the bonding procedure on shear bond strength of self etch and total etch adhesives, and to Compare the difference between the two contaminants in bond strengths.

Methods: 38 freshly extracted human mandibular and maxillary molar teeth, intact and caries free. Occlusal surface of the teeth was reduced at 2 mm deep leaving a flat dentinal surface. The teeth's were mounted on plastic jigs, filled with self-cured acrylic. The samples were randomly divided into 2 main groups ( $\mathrm{n}=19$ ) Group1 (self-etch) and Group2 (total-etch). Each groups were further subdivided based on contamination ( $\mathrm{n}=14)$ and non-contamination (control) ( $\mathrm{n}=5)$. Each contaminated group was subdivided into contaminated with blood $(\mathrm{n}=7)$ and saliva $(\mathrm{n}=7)$.

Results: Self-etch group, Non Contaminated group (control) showed the highest mean $( \pm \mathrm{SD})$ compressive strength $(24.4326 \pm 1.62734 \mathrm{MPa})$. The group contaminated with blood showed the least bond strength $(6.2573 \mathrm{MPa})$,followed by contamination with saliva (18.6 MPA). In the total-etch group Non contaminated (control) b2 group showed the highest mean $( \pm \mathrm{SD})$ compressive strength $(23.7247 \pm 0.81738 \mathrm{MPa})$. The group contaminated with blood showed the least $(3.8380 \mathrm{MPa})$, followed by the group contaminated with saliva (19.6805 Mpa).
\end{abstract}

Significance: In the self etch and total etch group, blood contamination showed the least bond strength followed by saliva contamination which had a slightly better adhesion when compared to blood contamination.

\section{Introduction}

The increase in demand \& use of esthetic restorations by patients and clinical practitioners in the present era has led to intensive research of adhesive materials. Contamination is one of the most common problems encountered during bonding restorative procedures, which can lead to mainly reduction in the bond strength of the composite especially when rubber dam isolation is not durable. Many carious lesions, which require the use of dentin bonding agents, are located on areas that are difficult to isolate especially when the site is near or at the gingival margin and, therefore, dentin contamination with saliva and blood is more likely to occur. In this context, the contamination of the operatory field is a recurrent reality that emphasizes the value of studies in this area. Contemporary adhesive systems can be classified into two groups: total-etching and self-etching systems.

Self-etching adhesive systems don't require acid etching and removal of the smear layer and smear plugs. This reduces the potential for post-operative sensitivity and bonding problems associated with movement of dentinal fluid through patent dentinal tubules. Technique-sensitivity associated with bonding to a dehydrated collagen matrix is also eliminated. Self etch adhesive systems supply increased user reliability with faster application as well as a decreased number of application steps and components. Although this reduces the risk of saliva contamination, it may sometimes be impossible to maintain a dry operative field after the self etch adhesive application. Total-etch systems combine the functions of the dentine primer and bonding agent in one-bottle. Blood contamination of the adhesive surfaces may affect the bond strengths of adhesive resins. Recent studies have evaluated the effect of blood contamination of adhesives to dentin using different testing methods, showing a significant reduction in bond strength values. However, the effect of blood and saliva contamination on the adhesive properties of these newer adhesive systems has not been fully understood. Shear and Micro-tensile tests are the most common methods used for determining the bond strengths of adhesive systems, revealing valuable clinical information.

Therefore the purpose of this in vitro study is to evaluate and compare the effect of saliva and blood contamination on different steps of restorative procedures on shear bond strength of self-etch and total etch adhesives to dentin, and to compare the difference in bond strength between the two contaminants.

The null hypothesis tested was that blood and saliva contamination would not affect the shear bond strength of these newer adhesives to dentin.

Correspondence to: Kaltham ALUmairi, Dental Intern, Riyadh colleges of Dentistry and Pharmacy, Saudi Arabia, E-mail: kaltham.a.alumairi@student.riyadh.edu.sa

Key words: self-etch adhesive, total-etch adhesive, bond strength, saliva, blood, contamination

Received: April 28, 2017; Accepted: May 18, 2017; Published: May 20, 2017 


\section{Materials and methods}

38 freshly extracted human mandibular and maxillary molar teeth, intact and caries free, were used in the study. The teeth's were stored in distilled water. Occlusal surface of the teeth was reduced at $2 \mathrm{~mm}$ deep leaving a flat dentinal surface and polished with 600-grit abrasive for 30 seconds.The teeth's were mounted on plastic jigs, filled with self- cured acrylic. The samples were randomly divided into 2 main groups $(n=19)$ based on the adhesive used.

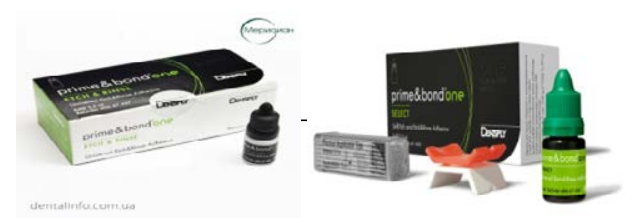

Group 1 was self etch using adhesive prime \& bond one select selfetch and etch\& rinse adhesive and Group 2 was total etch using adhesive prime \& bond one Etch \& rinse Universal Etch \& Rinse Adhesive. Each groups were further subdivided based on contamination and noncontamination (control) $(\mathrm{n}=5)$. Each contaminated group was again subdivided into those contaminated with blood and saliva $(n=7)$.

In Group 2, total etch, phosphoric acid 37\% was used for 15 seconds then rinsed for 10 seconds with water stream, followed by a gentle blast of air for 10 seconds to dry the surface before bonding procedure.

Contamination Group 1A (1Aa blue $n=7)$ : The dentin surfaces of the specimens were contaminated with blood (Group 1Aa) for 20seconds using a micro brush. After the contamination, Surface rinsed for 10 seconds with water stream, followed by a gentle blast of air for 10 seconds to dry the surface.

Contamination Group 1A (1Ab green-red $n=7)$ : The dentin surfaces of the specimens were contaminated with saliva (Group 1Ab) for 20seconds using a micro brush. After the contamination, Surface rinsed for 10 seconds with water stream, followed by a gentle blast of air for 10 seconds to dry the surface.

Non-contaminated (control) Group1B (1B Black n=5): In control group, the specimens were not contaminated with either saliva or blood.

Contamination Group 2A (2Aa red $n=7)$ : the dentin surfaces of the specimens were contaminated with blood (Group 2Aa) for 20seconds using a micro brush. After the contamination, Surface rinsed for 10 seconds with water stream, followed by a gentle blast of air for 10 seconds to dry the surface.

Contamination Group 2A ( $2 \mathrm{Ab}$ 2green $\mathrm{n}=7$ ): the dentin surfaces of the specimens were contaminated with saliva (Group 2Ab) for 20 seconds using a micro brush. After the contamination, Surface rinsed for 10 seconds with water stream, followed by a gentle blast of air for 10 seconds to dry the surface.

Non-contaminated (control) Group 2B (2B Black-red n=5): In control group, the specimens were not contaminated with either saliva or blood

After all, Self-etch and total-etch adhesives were applied to dentin according to the manufacturers' instructions and light cured with a visible light curing unit for $20 \mathrm{sec}, 4 \mathrm{~mm}$ diameter and $2 \mathrm{~mm}$ height vinyl polysiloxane tube placed on top of dentin surface and composite packed into it and light cured for 40 seconds. After complete polymerization, the tube removed and specimens kept in distilled water, in incubator for $37^{\circ} \mathrm{C}$ then they were subjected for shear bond strength analysis using Instron machine result statically analyzed using scheffe's post-hoc analysis test.

\section{Results}

The following are the results of the samples subjected to shear bond strength analysis.

Group 2Ab (Contaminated with Slavia).

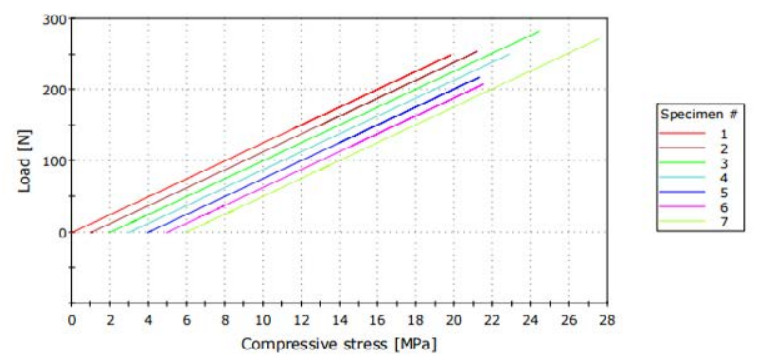

Group $1 \mathrm{Ab}$ (Contaminated with slavia).

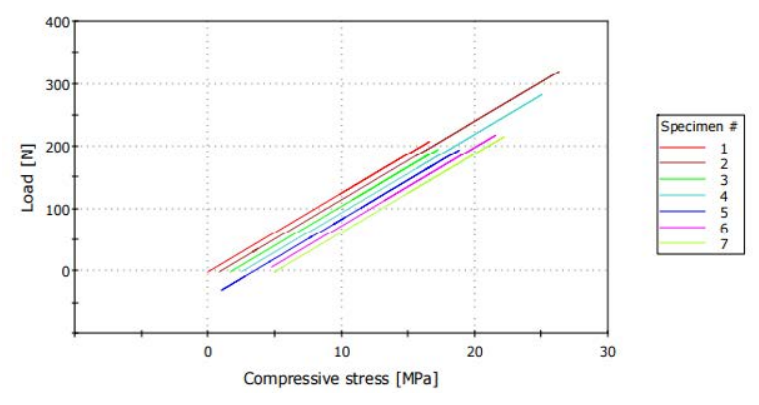

Group 1Aa (Contaminatedwith blood).

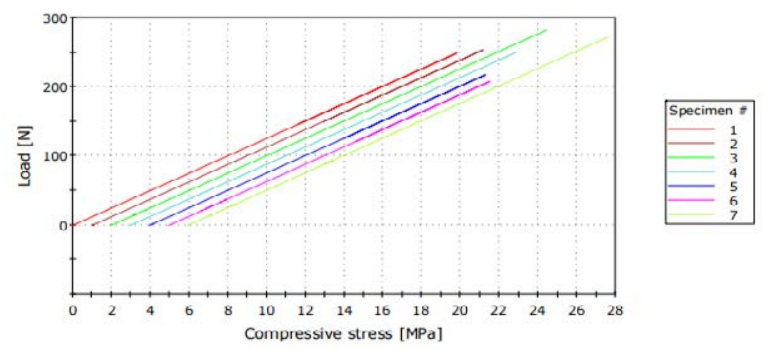

Group 1 Aa (contaminated with Blood)

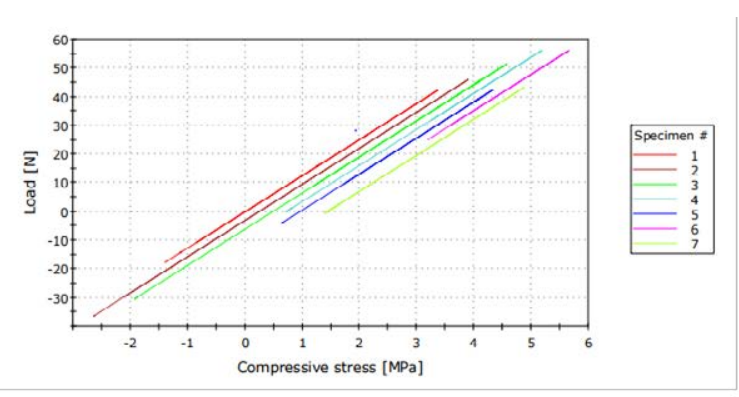


Group 2 Aa (contaminated with blood)
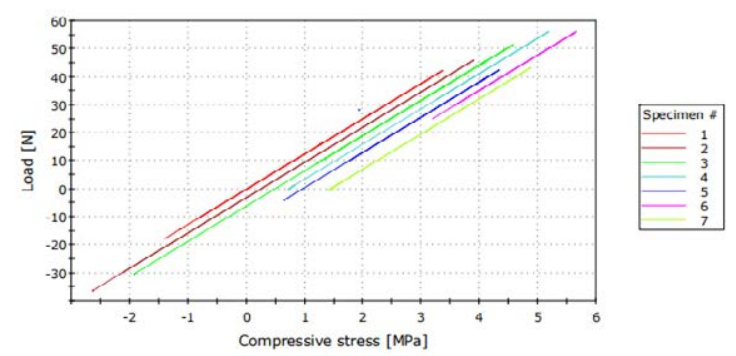

Group 1 B (non-contaminated)
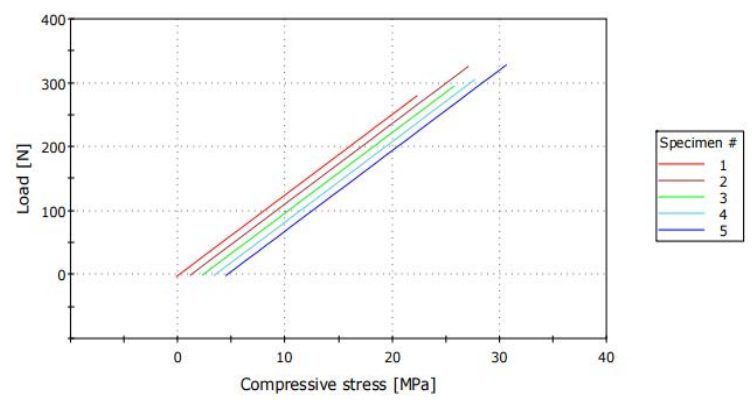

Group 2 B (non-contaminated)
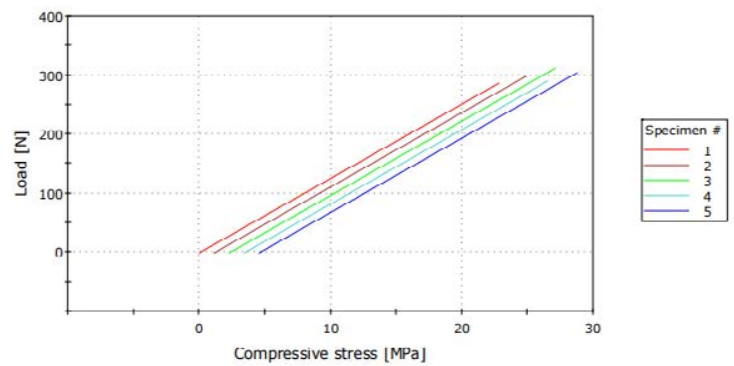

The data obtained in the present study was subjected to statistical analysis using one away ANOVA and scheffe's post hoc analysis test. In the self-etch group, Non Contaminated group (control) showed the highest mean $( \pm \mathrm{SD})$ compressive strength $(24.4326 \pm 1.62734 \mathrm{MPa})$. The group contaminated with blood showed the least bond strength (6.2573 MPa), followed by contamination with saliva (18.6 MPA) as mentioned in Figure 1.

In the total-etch group Non contaminated (control) b2 group showed the highest mean $( \pm$ SD) compressive strength (23.7247 \pm $0.81738 \mathrm{MPa})$. The group contaminated with blood showed the least (3.8380 MPa), followed by the group contaminated with saliva (19.6805 $\mathrm{Mpa}$ ) as mentioned in Figure 2.

Scheffe's post-hoc test for multiple comparison showed a statistically significant difference between the groups in Table $2(\mathrm{p} \leq 0.05)$.

Table 1.

- In self etch group, statistically significant difference in the mean compressive strength was found between groups that contaminated with saliva $1 \mathrm{Ab}$ and blood $1 \mathrm{Aa}(\mathrm{p}=0.000)$; with saliva $1 \mathrm{Ab}$ and non-contaminated (control) group $1 \mathrm{~B}(\mathrm{p}=0.002)$; and group that contaminated with blood $1 \mathrm{Aa}$ and non-contaminated (control) $1 \mathrm{~B}$ $(\mathrm{p}=0.000)$.

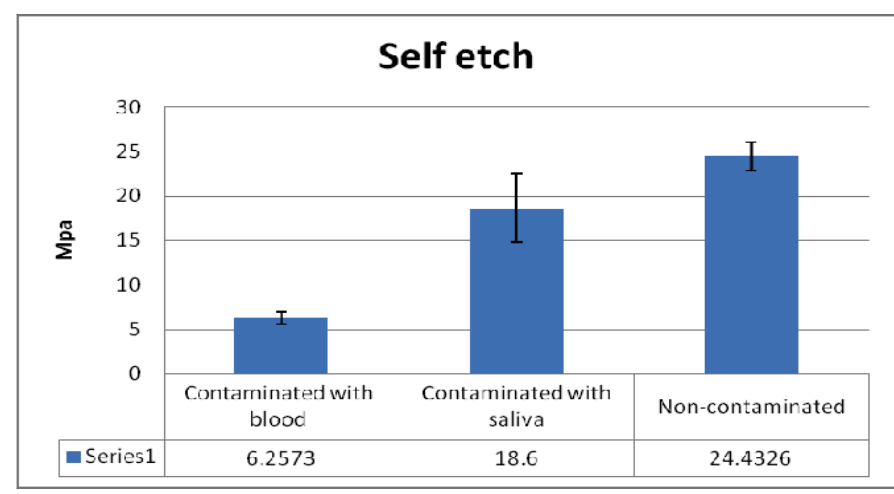

Figure 1. Mean $( \pm \mathrm{SD})$ compressive strength for self-etch group.

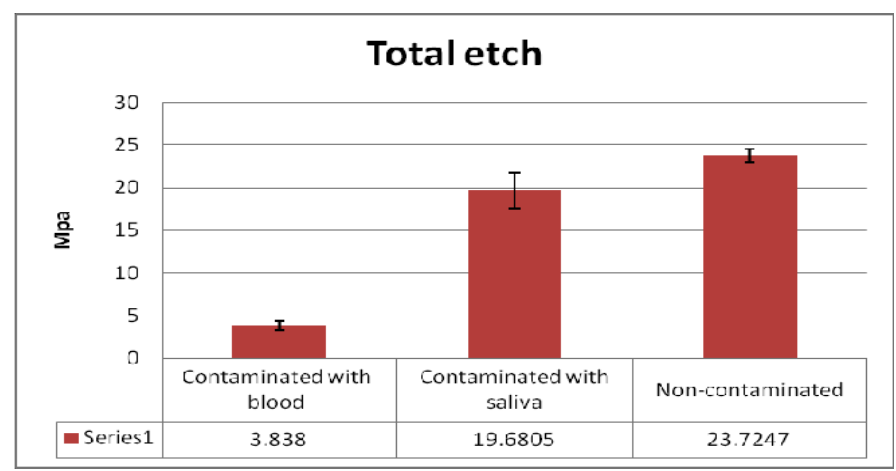

Figure 2. Mean $( \pm \mathrm{SD})$ compressive strength for total etch group.

- In the total etch group statistically significant difference was found between groups that contaminated with saliva $2 \mathrm{Ab}$ and Blood $2 \mathrm{Aa}(\mathrm{p}=0.000)$; and group that contaminated with blood 2Aa and noncontaminated/control B2 $(\mathrm{p}=0.000)$. Difference between group that contaminated with saliva $2 \mathrm{Ab}$ and non-contaminated/control B2 was not found to be statistically Significant $(\mathrm{p}=0.069)$.

- In comparison between the self etch and total etch group, there was a mean deference between self etch saliva \& total etch saliva $(\mathrm{MD}=2.4193)$, but not statically significant $(\mathrm{P}=0.442)$, the mean deference between self-etch blood \& total etch blood group was 1.0805 but, again not statically significant ( $\mathrm{p}=.962)$. In comparison between the control groups (non- contaminated self-etch and non-contaminated total etch) the main difference was .7079, and not statistically significant $(\mathrm{p}=.997)$, as mentioned in figure 3 .

\section{Discussion}

Blood and saliva contamination is one of the major clinical problem during any restorative dental treatment [1] according to the basic principle of adhesion, closer the contact between the adhesive and the adherent, stronger is their junction [2].

Dentin surface contamination can occur at two critical situations during the bonding procedure, after the tooth surface has been etched, and / or after the adhesive system had been applied. Due to this, the bonding can be compromised at both these situations. In this study, the negative effect of blood and saliva contaminations on the bond strength to dentin and resin composite were significant in all contaminated groups. In this study, the influence of saliva and blood contamination of total etch adhesive system and self-etch adhesive system using a microshear bond strength test was conducted. 
Table 1. Multiple Comparisons

Compressive strength-Scheffe

\begin{tabular}{|c|c|c|c|c|c|c|}
\hline \multirow[t]{2}{*}{ (I) Group } & \multirow[t]{2}{*}{ (J) Group } & \multirow[t]{2}{*}{ Mean Difference (I-J) } & \multirow[t]{2}{*}{ Std. Error } & \multirow[t]{2}{*}{ Sig. } & \multicolumn{2}{|c|}{ 95\% Confidence Interval } \\
\hline & & & & & Lower Bound & Upper Bound \\
\hline \multirow[t]{5}{*}{ Group 2 CS Green } & Group 1 CS Green-Red & 1.0805 & 1.09050 & .962 & -2.7844 & 4.9454 \\
\hline & Group 1 B Blue & $13.4231^{*}$ & 1.09050 & .000 & 9.5582 & 17.2881 \\
\hline & Group 2 B Red & $15.8424^{*}$ & 1.09050 & .000 & 11.9775 & 19.7074 \\
\hline & Group 1 NC Black & $-4.7521^{*}$ & 1.19458 & .020 & -8.9859 & -.5183 \\
\hline & Group 2 NC Black-Red & -4.0442 & 1.19458 & .069 & -8.2780 & .1896 \\
\hline \multirow[t]{5}{*}{ Group 1 CS Green-Red } & Group 2 CS Green & -1.0805 & 1.09050 & .962 & -4.9454 & 2.7844 \\
\hline & Group 1 B Blue & $12.3426^{*}$ & 1.09050 & .000 & 8.4777 & 16.2076 \\
\hline & Group 2 B Red & $14.7619^{*}$ & 1.09050 & .000 & 10.8970 & 18.6269 \\
\hline & Group 1 NC Black & $-5.8326^{*}$ & 1.19458 & .002 & -10.0664 & -1.5988 \\
\hline & Group 2 NC Black-Red & $-5.1247^{*}$ & 1.19458 & .010 & -9.3586 & -.8909 \\
\hline \multirow[t]{5}{*}{ Group 1 B Blue } & Group 2 CS Green & $-13.4231^{*}$ & 1.09050 & .000 & -17.2881 & -9.5582 \\
\hline & Group 1 CS Green-Red & $-12.3426^{*}$ & 1.09050 & .000 & -16.2076 & -8.4777 \\
\hline & Group 2 B Red & 2.4193 & 1.09050 & .442 & -1.4456 & 6.2842 \\
\hline & Group 1 NC Black & $-18.1752^{*}$ & 1.19458 & .000 & -22.4091 & -13.9414 \\
\hline & Group 2 NC Black-Red & $-17.4674^{*}$ & 1.19458 & .000 & -21.7012 & -13.2335 \\
\hline \multirow[t]{5}{*}{ Group 2 B Red } & Group 2 CS Green & $-15.8424^{*}$ & 1.09050 & .000 & -19.7074 & -11.9775 \\
\hline & Group 1 CS Green-Red & $-14.7619^{*}$ & 1.09050 & .000 & -18.6269 & -10.8970 \\
\hline & Group 1 B Blue & -2.4193 & 1.09050 & .442 & -6.2842 & 1.4456 \\
\hline & Group 1 NC Black & $-20.5945^{*}$ & 1.19458 & .000 & -24.8284 & -16.3607 \\
\hline & Group 2 NC Black-Red & $-19.8867^{*}$ & 1.19458 & .000 & -24.1205 & -15.6528 \\
\hline Group 1 NC Black & Group 2 NC Black-Red & .7079 & 1.29030 & .997 & -3.8652 & 5.2809 \\
\hline
\end{tabular}

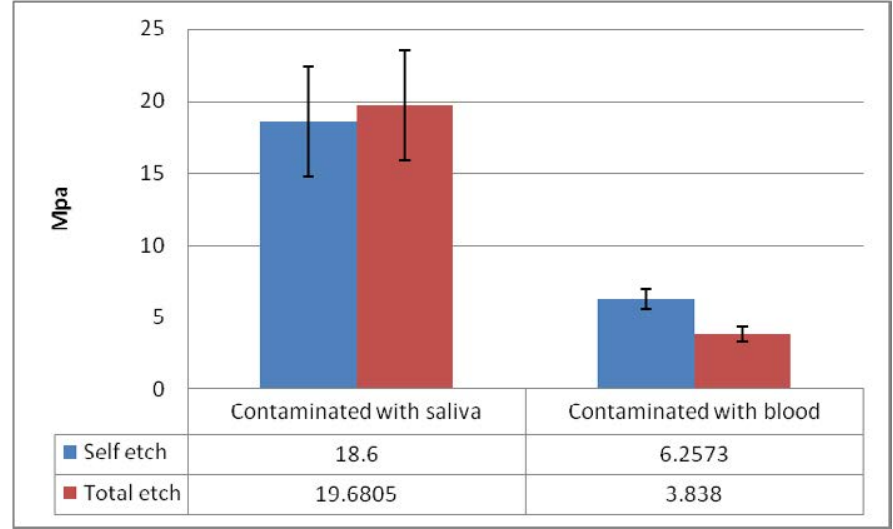

Figure 3. Comparison between self-etch and total etch.

According to our study, blood contamination has the highest effect on total etch adhesive systems. This might be due to the left over of blood contaminates in the dentin surface and also cost collagen fibers to collapse, preventing adhesive monomers to infiltrate. The blood protein components trapped on the dentin surface interferes with the bonding agent ability to form a uniform surface coating [1]. Resin tags formed on air-dried dentin surfaces were found to be fewer and much shorter than that in control conditions and blood contamination prevents adhesive infiltration into dentin tubules [3]. Our study is similar to the study done by Kaneshima et al. and Abdalla et al. [1,4], which showed decreased in shear bond strength when blood contamination occurred before the adhesive system application. Blood residues or reactants obstructing the dentin tubules can inhibit primer infiltration into dentin, thus interfering with hybrid layer formation $[1,4]$.

Saliva contamination has the highest effect on self-etch adhesive system. This might be due to the adsorption of glycoproteins to the poorly polymerized adhesive surface, thus preventing adequate polymerization rinsing of the contaminants after adhesive application could have disrupted the oxygen inhibited and un-polymerized layer, there by compromising the co-polymerization with subsequent resin layer [5-7] this is similar to this study done by Yoo et al. [8] which showed saliva contamination severely affected the bond strength to the self etch adhesive system.

The total-etch technique is still considered the gold standard for bond strength to enamel and dentin, and so, in our study self-etch adhesive systems have been compared to these to assess the relative bond strength with each.

Total-etch systems use a phosphoric acid step to dematerialize tooth surfaces. The acid present helps to create porosities, into which the adhesive can penetrate. On dentin, the acid etch removes the smear layer and exposes collagen fibers, allowing the adhesive to penetrate and interlock with the fibers. However, when using total-etch systems, there is a risk of over-drying which causes the collagen fibers to collapse. And if the primer and adhesive are applied to these collapsed fibers, instead of infiltrating into upright collagen fibers, the result can be poor adhesion [9].

Self-etching systems are generally less technique sensitive compared to systems that utilize separate acid conditioning and rinsing steps. Collapse of the air-dried, demineralized collagen is prevented as the smear layer-retained dentin is simultaneously demineralized and polymerized in situ. The material is designed to surround the collagen fibers in the dentin, enabling it to create a hybrid layer on wet or dry surfaces. One-bottle self-etch systems typically combine hydrophilic and hydrophobic agents in the same bottle; with $\mathrm{pH}$ levels ranging from 1.0 to 2.7 [10]. The lower acidity reduces the risk of over-etching and post-operative sensitivity.

The results from the present study clearly indicated that, when the dentin surface was contaminated with either blood or saliva, it adversely affected the bond strength.

It is most likely that the contaminants may have remained on the 
dentin surface, thus interfering with the bonding of adhesive system to resin cement. Therefore, the most important factor for an optimal bonding is to avoid any type of contamination. However, furthers studies varying the conditions, specially the laboratory technique, using a bigger sample size and the adhesive systems used, are necessary for definitive conclusions [11-31].

\section{Conclusion}

Within the limitations of this in vitro study it can be conclude that:

1. In the self etch and total etch group, blood contamination showed the least bond strength followed by saliva contamination, which had a slightly better adhesion when compared to blood contamination.

2. In comparison between self etch and total etch groups, saliva contamination on self etch group caused a lower bond strength to dentin than total etch group; but with blood contamination, total etch group caused a lower bond strength to dentin than self etch adhesives.

3. The null hypothesis that saliva and blood contamination would not affect the dentine microshear bond strength of self-etch \& total-etch adhesives systems was rejected except on total etch saliva contamination groups

\section{Acknowledgments}

We would like to thank King Saud University the Research center for the permission to use the universal testing (INSTRON machine) and also to Dr. Ashwin for helping with the statistical part.

\section{References}

1. Abdalla AI, Davidson CL (1998) Bonding efficiency and interfacial morphology of onebottle adhesives to contaminated dentin surfaces. Am J Dent 11: 281-285. [Crossref]

2. Baier RE, Shafrin EG, Zisman WA (1968) Adhesion: mechanisms that assist or impede it. Science 162: 1360-1368.

3. Pashley DH, Carvalho RM (1997) Dentine permeability and dentine adhesion. J Dent 25: $355-372$.

4. Kaneshima T, Yatani H, Kasai T, Watanabe EK, Yamashita A (2000) The influence of blood contamination on bond strengths between dentin and an adhesive resin cement. Oper Dent 25: 195-201. [Crossref]

5. Hegde MN, Hegde P, Shetty SK (2008) The influence of salivary contamination on the shear bond strength of two newer generation dentin bonding agents- An in vitro study. J Conserv Dent 11: 127-130. [Crossref]

6. Koppulu M, Gogala D, Mathew VB, Thagala V, Deepthi M, et al. (2012) Effect of saliva and blood contamination on the bond strength of self-etching adhesive systemAn in vitro study. J Conserv Dent 15: 270-273. [Crossref]

7. Nagpal R, Manuja N, Tyagi SP, Singh UP (2011) In vitro bonding effectiveness of self-etch adhesives with different application techniques: A microleakage and scanning electron microscopic study. J Conserv Dent 14: 258-263. [Crossref]

8. Yoo HM, Oh TS, Pereira PNR (2006) Effect of Saliva Contamination on the Microshear Bond Strength of One-step Self-etching Adhesive Systems to Dentin. Operative Dentistry 31-1,127-134. [Crossref]

9. Feuerstein O, Matalon S, Slutzky H, Weiss EI (2007) Antibacterial properties of selfetching dental adhesive systems. J Am Dent Assoc 138: 349-354. [Crossref]

10. Perdigão J, Carmo ARP, Geraldeli S (2005) Eighteen-month clinical evaluation of two dentin adhesives applied on dry vs moist dentin. $J$ Adhes Dent 7: 253-258. [Crossref]

11. Benderli Y, Gokce K, Buyukgokcesu S (1999) In vitro shear bond strength of adhesive to normal and fluoridated enamel under various contaminated conditions. Quintessence Int 30: 570-575. [Crossref]

12. Bishara SE, Oonsombat C, Ajlouni R, Denehy G (2002) The effect of saliva contamination on shear bond strength of orthodontic brackets when using a self-etch primer. Angle Orthod 72: 554-557. [Crossref]

13. Soares CJ, Branco CA, Soares PBF, Fonseca RB, Carlo HL, et al. (2007) Effect of blood contamination during adhesive restorative procedures on dentin-resin cement shear bond strength. Braz J Oral Sci 6: 1320-1325.

14. Chang SW, Cho BH, Lim RY, Kyung SH, Park DS, et al. (2010) Effects of blood contamination on microtensile bond strength to dentin of three self-etch adhesives. Oper Dent 35: 330-336. [CrossRef]

15. Dietrich T, Krämer M, Lösche GM, Wernecke KD, Roulet JF (2000) Influence of dentin conditioning and contamination on the marginal integrity of sand- wich class II restorations. Oper Dent 25: 401-410. [Crossref]

16. Eiriksson SO, Pereira PN, Swift EJ, Heymann HO, Sigurdsson A(2004) Effects of blood contamination on resin-resin bond strength. Dent Mater 20: 184-190. [Crossref]

17. El-Kalla IH, García-Godoy F (1997) Saliva contamination and bond strength of singlebottle adhesives to enamel and dentin. Am J Dent 10: 83-87. [Crossref]

18. Darabi F, Tavangar M, Davalloo R (2012) Effect of different decontamination procedures from a saliva- contaminated cured bonding system (Single Bond). Dent Res J 9: 399-403. [Crossref]

19. Fritz UB, Finger WJ, Stean H (1998) Salivary contamination during bonding procedures with a one-bottle adhesive system. Quintessence Int 29: 567-572. [Crossref]

20. Grégoire G, Guignes P, Nasr K (2009) Effects of dentine moisture on the permeability of total-etch and one-step self-etch adhesives. J Dent 37: 691-699. [Crossref]

21. Hitmi L, Attal JP, Degrange M (1999) Influence of time point of salivary contamination on dentin shear bond strength of 3 dentin adhesive systems. $J$ Adhes Dent 1: 219-232. [Crossref]

22. Kim J, Hong S, Choi Y, Park S (2015) The effect of saliva decontamination procedures on dentin bond strength after universal adhesive curing. The Korean Academy of Conservative Dentistry 1-7.

23. Johnson ME, Burgess JO, Hermesch CB, Buikema DJ (1994) Saliva contamination of dentin bonding agents. Oper Dent 19: 205-210. [Crossref]

24. Hegde MN, Hegde P, Chandra CR (2012) Morphological evaluation of new total etching and self-etching adhesive system interfaces with dentin. $J$ Conserv Dent 15 : 151-155. [Crossref]

25. Yalçin M, Simsek N, Keles A, Ahmetoglu F, Dündar A, et al. (2013) Effect of salivary contamination on micro-tensile bond strength of self-etch adhesives systems after bonding procedure. Journal of Restorative Dentistry 1: 55-59.

26. Powers JM, O'Keefe KL, Pinzon LM (2003) Factors affecting in vitro bond strength of bonding agents to human dentin. Odontology 91: 16. [Crossref]

27. Robert M Justin, Hemalatha Paranthaman, AG Rajesh, Ranjith P Varghese,LM Ranganath (20012) Effect of salivary contamination on the bond strength of total-etch and self-etch adhesives systems: an in vitro study. J Contemp Dent Pract 13: 655-660. [Crossref]

28. Munaga S, Chitumalla R, Kubigiri SK, Rawtiya M, Khan S, et al. (2014) Effect of saliva contamination on the shear bond strength of a new self-etch adhesive system to dentin. J Conserv Dent 17: 31-34. [Crossref]

29. Van Schalkwyk JH, Botha FS, van der Vyver PJ, de Wet FA, Botha SJ (2003) Effect of biological contamination on dentin bond strength of adhesive resins. SADJ 58: 143147. [Crossref]

30. Xie J, Powers JM, Mc Guckin RS (1993) In vitro bond strength of two adhesives to enamel and dentin under normal and contaminated conditions. Dent Mater 9: 295-299. [Crossref]

31. Yazici AR, Tuncer D, Dayangaç B, Ozgünaltay G, Onen A (2007) The effect of saliva contamination on microleakage of an etch-and-rinse and a self-etching adhesive. $J$ Adhes Dent 9: 305-309. [CrossRef]

Copyright: (C)2017 ALHussain H. This is an open-access article distributed under the terms of the Creative Commons Attribution License, which permits unrestricted use, distribution, and reproduction in any medium, provided the original author and source are credited. 